\title{
Compound stimulus transfer ${ }^{1}$
}

\author{
WILLIAM W. GRINGS and ARTHUR \\ ZEINER, ${ }^{2}$ University of Southern \\ Califormia, Los Angeles, Calif. 90007
}

An earlier study examining transfer of conditioned response from compound stimuli to component stimuli was repeated with design changes to emphasize differences among responses to the components. Discrimination conditioning of the GSR to colored light pairs was used with 30 student $S$ s. The previous results, which showed a lack of transfer of differential responding from acquisition on stimulus pairs to tests on single components, were replicated. Data are presented to show that the results are not due to lack of acquisition training.

It has frequently been reported that after conditioning to a simple compound stimulus has occurred and tests of responses to component stimuli are made, the responses to components are of a smaller magnitude than response to the compound. This effect has been noted to be a function of such variables as the relative intensity of component stimuli (Razran, 1965) and to differ for different degrees of learning (generally the greater the amount of training the less the transfer from compound to component). Most investigations of these phenomena have employed simple conditioning procedures rather than discrimination conditioning.

A recently reported study (Grings, 1969) described an experiment in which classical discrimination conditioning of the GSR was established to two simple compound stimuli (pairs of colored lights). One pair was reinforced and the second pair was not reinforced. After differential responding to compounds had been established, test trials were introduced on components from the original pairs. There was no evidence of differential responding to components, i.e., components from the reinforced pair did not elicit larger GSRs on test trials than did components from nonreinforced pairs. It was concluded that little or no transfer occurred from training on compounds to tests on components.

Several features of the previous experiment led to the decision to repeat it with some procedural modifications. In the previous experiment test trials were numerous since all compounds and components were tested. One obvious result of so many test trials was a significant amount of extinction (and consequent reduction in magnitude of responding during test trials). Order of stimulus presentation was systematically rotated making it possible for some of the tests on components to occur quite late in the test series. In addition, two of the test trials involved new pairs, or new combinations of components from the original conditioned compound stimulus. These new compound stimuli were found to elicit larger responses than any of the other test stimuli. The presence of such "strange" pairs could have affected responses to component stimuli.

The present study is a replication of the previous investigation giving preferential order treatment to tests of components. The first two trials at the conclusion of acquisition were devoted to tests of components. Later tests of compound stimuli from original learning and additional tests on components were used for rechecking transfer of original learning effects as related to the original compound stimuli and to evaluate relative magnitudes of response to components in order to test an extinction hypothesis. In the second test of components, stimuli were classified according to magnitude of response elicited as either (D) dominant or (N) nondominant. For extinction, the original conditioning group was divided in to three subgroups. One subgroup was extinguished on the dominant component, the second subgroup was extinguished on the nondominant component, and the third subgroup was extinguished on a component from the nonreinforced pair. After a series of extinction trials, transfer of extinction from component to compound was tested by presenting the originally reinforced compound stimulus.

The questions to be answered were: (1) whether, after discrimination learning has been established to two compound stimuli (pairs of dots of light) such that one compound $(++)$ elicits a response to a greater extent than a second compound (-), the difference in response tendency would transfer to the components; and (2) whether extinction trials administered to selected components would lead to extinction of response to the compound.

\section{METHOD}

Thirty volunteer college students served as $\mathrm{Ss}$ for approximately $1 \mathrm{~h}$ each. Conditioned stimuli were small colored dots produced by projecting through Wratten filters onto a ground glass screen in front of the $\mathrm{S}$. Colors were matched for brightness, and combinations of colors were rotated from $S$ to $S$. Half of the group was given eight preconditioning trials on each of two stimuli consisting of two combinations of the paired colors, and the second half of the group was given the same number of adaptation trials but on four individual stimuli presented in random blocks of eight.

The GSR was picked up as a dc resistance from the first and third fingertips of the nonpreferred hand by $1 / 2 \times 5 / 8$ in. silver electrodes coated with electrode paste and taped to the fingers. GSR electrodes led to a modified Wheatstone bridge whose output was delivered to an Offner Type $R$ Dynograph. The UCS was a dc shock from a Grass Model S-5 stimulator delivered through 12-mm-diam silver electrodes placed 2 in. apart on the volar surface of S's arm opposite the hand to which the GSR leads were attached. Shock intensity was set by $S$ at his subjective maximum at the outset of the experiment.

Conditioned stimulus duration was $1.0 \mathrm{sec}$ and UCS duration was $.5 \mathrm{sec}$. The interval between CS and UCS onsets was $.5 \mathrm{sec}$, leading to an overlap of stimuli for the last $.5 \mathrm{sec}$ that the $\mathrm{CS}$ was on. Interstimulus intervals were controlled by Hunter timers. Intervals between trials were varied systematically between 15,20 , and $25 \mathrm{sec}$. A special task was used to ensure attention of $S$ to the visual stimuli. He was provided with a switch, which turned on soft music in the laboratory and was told that when the word "ready" was given by the E he was to depress the switch and hold it until the colored light went off.

Two compound stimuli were used for the acquisition series, one reinforced and the other not reinforced. Stimuli were presented in blocks of eight trials. After two random blocks of eight trials a mid-acquisition test trial was introduced where each compound stimulus was presented once without shock. This was followed by two more random blocks of eight trials. Immediately after acquisition, two series of four trials each (compounds and components) were administered, with order determined from a systematic order sheet. The first two trials always tested one component from each of the previously reinforced and previously nonreinforced compounds, with order counterbalanced so that components from each of the original compounds would occur equally of ten in the first test trial position.

Table 1

Mean Magnitudes of Response to Originally Conditioned Stimuli. $\mathbf{N}=\mathbf{3 0}$. Unit: Square root of conductance change in micromhos.

\begin{tabular}{|c|c|c|c|}
\hline Stimulus & $\begin{array}{c}\text { Mid } \\
\text { Acquisition }\end{array}$ & $\begin{array}{c}\text { First } \\
\text { Posttest }\end{array}$ & $\begin{array}{l}\text { Second } \\
\text { Posttest }\end{array}$ \\
\hline $\begin{array}{r}\text { Reinforced } \\
\text { Pair }(++)\end{array}$ & 1.35 & 1.42 & 1.32 \\
\hline $\begin{array}{l}\text { Nonreinforced } \\
\text { Pair (--) }\end{array}$ & .98 & .98 & .74 \\
\hline $\begin{array}{l}\text { Difference } \\
t\end{array}$ & $\begin{array}{r}.37 \\
3.45\end{array}$ & $\begin{array}{r}.44 \\
3.13\end{array}$ & $\begin{array}{r}.58 \\
4.14\end{array}$ \\
\hline p & .01 & .01 & .01 \\
\hline
\end{tabular}


Table 2

Mean Magnitudes of Response to Components from the Original Pairs on Transfer Test Trials $\mathbf{N}=\mathbf{3 0}$

\begin{tabular}{lcc}
\hline Components & $\begin{array}{c}\text { Transfer } \\
\text { Trial I }\end{array}$ & $\begin{array}{c}\text { Transfer } \\
\text { Trial II }\end{array}$ \\
\hline From reinforced pair (+) & 1.11 & 1.15 \\
From nonreinforced pair (-) & 1.08 & .98 \\
Difference & .03 & .17 \\
$t$ & .20 & 1.55 \\
\hline
\end{tabular}

This was followed by two test trials on the original learning compound stimuli, then four more test trials on components.

For extinction, Ss were divided randomly into three groups. In the dominant component group, extinction trials were administered to the component from the original reinforced compound which yielded the largest magnitude of response on postacquisition tests; in the nondominant component group, extinction trials were given the component from the original reinforced compound which gave the smaller magnitude of response on postacquisition tests. The third, control, group received extinction trials on one of the components from the nonreinforced compound stimulus. Four extinction trials on the selected components were followed by a test of the compound stimulus originally reinforced in acquisition. This was followed by four more extinction trials on components and another test of the compound.

\section{RESULTS}

Responses with a latency from 1 to $6 \mathrm{sec}$ following CS onset on test trials were read from start of response to peak, in the unit square root of change in conductance. This value was averaged for test trials on originally trained compounds to evaluate for degree of initial discrimination conditioning. That information is shown in Table 1 where it can be seen that a significant difference in magnitude of response to reinforced and nonreinforced compounds occurred at the mid-acquisition test trial and at two postacquisition test points.

To test for transfer of differential response from compounds to components, means for the component from the reinforced compound stimulus and the component from the nonreinforced compound stimulus on two posttest trials were computed and are shown in Table 2 . As in the previous study, there is no evidence of transfer of differential responding, unless note is taken of the fact that such differences as occurred are in the expected direction and increase in magnitude as extinction progresses.

Comparison of magnitudes of response to the compound stimulus $(++)$ after extinction trials on various component stimuli suggested a transfer of extinction effect determined in part by the strength of the component. The response was smallest for the dominant component group, intermediate for the nondominant group, and maximum for the control group. These differences, however, were only marginally significant $(\mathrm{p}=.10)$.

\section{DISCUSSION}

Present results agree with those in the previous study, showing that differential responding established to simple compound stimuli composed of pairs of colored lights does not transfer to produce differential responding to components. Presumably, initial conditioning was sufficient to provide clear differentiation for the $S$ between compound stimuli in acquisition and component stimuli as tested at the conclusion of acquisition. Considerations for possible further exploration were provided by weak evidence that extinction of the components will transfer to extinction of the compound and that the degree of transfer is related to the dominance of the component in original conditioning.

\section{REFERENCES}

GRINGS, W. W. Transfer of response from compound conditioned stimuli. Psychonomic Science, 1969, 15, 187-188.

BAKER, T. W. Properties of compound conditioned stimuli and their components. Psychological Bulletin, 1968, 70, 611-625.

RAZRAN, G. Empirical codifications and specific theoretical implications of compound stimulus conditioning: Perception. In W. F. Prokasy (Ed.), Classical conditioning. New York: Appleton-Century-Crofts, 1965.

$$
\text { NOTES }
$$

1. This research was supported in part by Grant MH-03916 from the National Institute of Mental Health.

2. Now at University of California Medical Center, San Francisco, California.

\section{Probability learning with words}

BRUCE L. HANSON, LOWELL M. SCHIPPER, and RICHARD W. BRISLIN, The Pennsylvania State University, University Park, Pa. 16802

In two experiments in multiple probability learning, Ss were trained with conditional probabilities $\left(\pi_{i}\right)$ of outcomes associated with two or three stimulus adjectives. After training, they predicted the same outcomes without feedback, but stimuli now included synonyms and antonyms of the original stimulus words. Responses to antonyms were reliably different from synonyms in the direction of complementarity $\left(1-\pi_{i}\right)$, even when associative values of antonyms were considerably higher than synonyms. By allowing for complementary responses, this paradigm provides a particularly useful tool for the examination of semantic and associative properties of words.

The principal purpose of these experiments was to examine the generalization of probabilistic training with words as stimuli-or predictors-to synonyms and antonyms of those words. The basic model for this method, using nonmeaningful stimuli as predictor cues, has been previously studied in this laboratory (Gentile \& Schipper, 1966; Schipper, 1967; among others). Ss learned conditional probabilities $\left(\pi_{\mathrm{i}}\right)$ of occurrence of a particular event (red light) given single predictors (green lights) in arrays of two, three, four, or five predictors. After training, occurrence of the event light was predicted, without feedback, from the individual and combinations of predictor lights.

Substitution of words for green lights as predictors in learning and substitution of additional words for light combinations provide a new way to examine the semantic and associative values of word pairs. Although these properties have been extensively studied by the mediated generalization paradigm (Jenkins, 1963; Mandler, 1963), only half of the potential generalization scale was available. There was either some degree of generalization, or there was none. The methods did not allow for a "negative generalization," an opposite response. Ss are, in the studies to be reported here, provided the opportunity to respond in a complementary manner to synonyms and antonyms and other (neutral?) words.

\section{METHOD \\ Experiment 1}

Three predictor words were selected on the basis of the high association value of their synonyms and antonyms, but with respective antonyms higher than synonyms (Shapiro \& Palermo, 1968). The words were FAST with associates SWIFT and SLOW, BIG with associates LARGE and SMALL, and ROUGH with associates COARSE and SMOOTH. Three nouns, DOOR, LAMP, and PARK, were selected as control words because of their low association with all nine test words.

Stimulus words were projected individually on a screen for $4 \mathrm{sec}$ during which time Ss predicted whether the following slide projected would be a five-pointed star or a blank slide. Predictions were made by pressing one of two buttons on hand-held response boxes. Consecutive 